\title{
FOODIES IN THE UK: A SENSE OF SELF, CONNECTION AND BELONGING BEYOND THE PASSION?
}

\author{
Dr Marwa Gad Mohsen \\ University of Worcester \\ United Kingdom \\ Email: m.gadmohsen@worc.ac.uk
}

\begin{abstract}
The global rise of the Foodie movement has attracted some research attention as well as critique in the food industry trend followers, but little research attention in marketing research. The present study looks at the 'Foodie' phenomenon in the UK and aims to extend how the notion has been coined in literature through a qualitative investigation of a sample of self-professed Foodies. The objective is to provide an in-depth understanding of what it means to be a Foodie at the individual and group levels, probing attitudes, motivations and self-awareness. Results indicate that the term Foodie cannot be used as an implicit definition of someone 'simply interested in food'; the capacity of the Foodie may be dependent on individual involvement and the level of importance along the five emerging themes; these being: Learning and discovery; Pleasure and enjoyment; Inspirational influences; Quality; and Experiencing food as an individual and in connection with others. Findings imply that there might be different levels of Foodies, leading to a start on developing a Foodie Typology. The study poses implications for food marketers and researchers that can assist in more effective segmentation, efficient targeting and tailored positioning, as well as opportunities for future research.
\end{abstract}

\section{Keywords}

Foodies, Discovery, Enjoyment, Inspiration, Connection, Sense-of-self 


\section{INTRODUCTION}

Food is intrinsic to life and existence via its ubiquitous power and significance. As Euromonitor (2013a, Online) reports, food is something "we all need, want, have too much or not enough of". However, beyond constituting a basic need, food connotations extend far beyond sustenance; it has undertones that relate to culture, norms, the socialization process and personal expression. The rise of the Foodie movement around the globe has attracted some research attention in the sociology literature, some critique in food industry trend followers, but little research attention in marketing and consumer research. The Foodie phenomenon blurs 'the lines between specialty and mainstream foods. Three-quarters $(76 \%)$ of U.S. adults enjoy talking about new/ interesting foods; $70 \%$ consider themselves knowledgeable about food; and 53\% regularly watch cooking shows, according to the National Association for the Specialty Food Trade's (NASFT) Specialty Food Consumers 2012' (Sloan 2013). Yet, more substantial facts and insights based on consumer research on 'Foodies' are yet to be developed in the UK.

Many questions arise in relation to the rise of the Foodie movement; for instance, who is 'the Foodie' and what does the term encapsulate? Is it a phenomenon that differs across cultures? Is it about a sophisticated culinary experience? Is it related to a deeper sense of self-expression and perceived identity? Or, is it about a collective food inspiration? In advancing associations between food as a physiological need and its more intricate perception as an emotional encounter, Foodies emerge possibly as a heterogeneous consumer group that requires further indepth exploration. According to a Food Statistics report by DEFRA (2014), "the food sector (excluding agriculture) increased by $51 \%$ between 2000 and 2012 while the whole economy increased by $57 \%$. The food sector has less scope for growth as there is a limit to consumer intake capacity and therefore it relies largely on quality improvements." These facts imply that effective food marketing is now more than ever about a richer acknowledgment of the reality of a new food consumer, one who is seeking more than just simple sustenance; food consumers are becoming more and more sophisticated and variably adventurous in their food purchase and consumption decisions. Hence, a more rigorous understanding of the attitudes, motivations and consumption patterns of a highly involved food consumer can enlighten marketers' efforts in profiling and reaching potentially targetable segments in such a lucrative market.

This study looks at the 'Foodie' phenomenon and Foodies in the UK; it aims to explore how the notion has been coined in existing literature and goes into a qualitative investigation of a sample of self-professed Foodies. The objective is to provide an in-depth understanding of what it means to be a Foodie at the individual and group levels, probing attitudes, motivations and selfawareness, thus highlighting connections among the inherent physical, social and marketing dimensions.

\section{LITERATURE REVIEW}

Food as a basic need is perhaps the most common reality for people regardless of their social, cultural or individual differences (Probyn 1999). Nonetheless, Yue (2003: p.159) explains that food consumers may expand the notion of eating to a more abstract level as a way to 'express different cultural meanings'. Supporting Fischler's (1988) view of the food self, Yue (2003) emphasizes the relationship between food and identity. In linking to the physical being, our food may narrate our psychological well-being and sense of self. As a dynamic function that can move 
from sacred to everyday in a powerful and influential way, Appadurai (1996) advances food as adaptable to individuals as well as situations in a versatile manner; it can hence be endorsed as both a commodity and a lifestyle choice. Poole (2012: Online) in his Guardian article criticizing an overwhelming Foodie culture deliberates on how "People with an overweening interest in food have been calling themselves Foodies since a Harper's \& Queens article entitled 'Cuisine Poseur' in 1984". The Foodie notion, nevertheless, has received little academic research attention, though it has been given varied delineations.

Various dictionary definitions of a Foodie simplistically coin the term as referring to someone who has a refined interest in the latest food fads or a highly sensuous enjoyment of food. Cairns, Baumann and Johnston (2010), in studying gender enactment and roles within the food culture, suggest that the term can be assigned to individuals with a passion for good food, experienced over a long period with dedication. Cairns et al.'s (2010) study did not include food industry professionals, which may signify that for them food professionals are not considered Foodies. Oxford Dictionary defines a Foodie as 'a person with a particular interest in food', with an exemplar phrase that pairs an 'avid Foodie' and a 'successful restaurateur', thus projecting that food professionals can be considered Foodies. The varying and imperfect extant definitions set the Foodie Phenomenon at a raw research stage, calling for more active investigations.

Probyn's (1999) work on eating, culture and society creates a foundation in placing food on a pleasure scale and exploring the idea of food having an identity; nevertheless, it does not go deeper into the pleasure of the individuals involved, or its influence on their identity. Euromonitor (2013a) notes a rise in food blogging as it provides a medium to engage in a Foodie culture online. Lifestyle thus emerges as a prominent factor at play; the increasing interest in the 'Foodie Culture' may explain increasing food TV shows and viewership, with celebrity chefs becoming lifestyle experts and 'actors in the gourmet foodscape' (Euromonitor 2013b). Yue (2003: p. 159) highlights how individuals may become 'incorporated into networks of production and exchange' through eating, thus touching both the material and virtual essences of producing and exchanging material foods as well as opinions and perceptions within the Foodie 'world'.

From a socio-economic consumption perspective, Bourdieu (1984) investigated the relationship between food consumption and social class, drawing upon 1960s' France and the different perceptions in food consumption between the working class and the bourgeoisie. Such an economic and social fusion is still relevant today, but how it applies to the contemporary food culture may have differed. Other than social class, there might be other variables that differentiate consumers' experiences with and of food. The marketing strategy and operational implications can feed into more effective segmentation, efficient targeting and tailored positioning. The study is one of the first attempts at exploring the idea of the 'Foodie experience', to assist food marketers in reaching out to the real Foodies given that a 'Foodie' may not be a given label, but rather one that is self-perceived and self-defined.

\section{METHODOLOGY}

A qualitative research approach was employed in this study due to the nature of its aim; an indepth examination of individual experiences to unveil elements of attitudes, motivations and self-awareness require a flexible and adaptable research approach better tackled through a qualitative study (Hennink, Hutter and Bailey 2011). An exploratory design helps to deconstruct 
the social implications surrounding this relatively new topic, given limited extant academic research on its peculiarities, especially from a marketing perspective.

As in interpretive studies, subjects can be viewed as 'social actors' (Saunders, Lewis and Thornhill 2012), hence participants in this study could offer their own interpretations of being a 'Foodie' in a sense-making discourse. Hence, the use of interviews and focus group was most suited for primary data collection to underpin the phenomenon where participants were early on informed that responses cannot be incorrect, but rather a perceived reflection of their opinions, feelings and elucidations. The researcher conducted 16 in-depth face-to-face interviews and 1 FG (of 6 participants) in the West Midlands of the UK in Summer' 2015 as a starting phase of this exploratory study. In terms of sampling, purposive sampling was used to reach the first 5 participants, followed by snowballing as Foodies share experiences and hence know others who could take part in the study. Data validity was undertaken through respondent validation by asking participants to check and corroborate samples of the transcripts and the emerging themes and categories. Inter-rater reliability was established through multiple coding where coding strategies and samples of data interpretation where cross-checked by an independent researcher (Barbour 2001); a high level of concordance and absence of disagreement over emerging themes did not call for further refining of coding frames.

The eligibility criteria for participation adopted Cairns et al.'s (2010) definition of a Foodie, with those included having 'a strong interest in or a passion for learning about and eating good food', but gender, age, social class, and whether or not they were food professionals, were not part of the criteria. This meant that the sample constituted individuals of any gender and age, with an avid interest in Food, high level of food involvement and who viewed themselves as Foodies, or almost so, regardless of whether or not they were working in the food industry; this latter part was a variation on Cairns et al.'s (2010) study of Foodies as it allowed for a more open-minded flexibility that endorsed other published views and definitions. The sample did not purport to represent the population of interest but was an attempt to enhance the profile of the sample frame for future studies. Yet, participants were both males and females of different ages, and with average levels of education and income.

The focus group allowed a collective opportunity for discussion and exchange of ideas aimed at enriching the data analysis, in addition to the in-depth interviews. As the findings from the analysis of the focus group data were not different from those obtained from the in-depth interviews, all results were combined together, as discussed in the next section. The study's participants were asked a series of open-ended questions, exploring their opinions of who a Foodie is; whether/why they consider themselves to be Foodies; how 'others' fit in with such an experience; use of media and opinion global on food programs; shopping experiences and dining preferences; and their perspectives on ethical food trends.

\section{DATA ANALYSIS AND FINDINGS}

Data was transcribed and thematic analysis was used to find patterns and common themes. Six stages of thematic analysis were applied following Braun and Clarke (2006); the first comprised familiarization with the data to enable immersion and engagement as a foundation base, followed by generating initial codes which are close to the raw data without over-interpretation. The third phase involved using thematic mapping, where codes were conceptualized through sifting and 
choosing the most significant ones based on frequency and conviction, in line with the study's aim and objectives. In the fourth phase of the analysis, emergent themes were actively reviewed to establish final themes through evolving meanings and interpretations; some sub-themes branched out then from the main domains, which were then named and defined following the trends in the findings. Based on the findings, five key themes emerged, with some related subthemes. The key areas are: Learning and discovery; Pleasure and enjoyment; Inspirational influences; Quality; and Experiencing food as an individual and in connection with others, as discussed in more detail next.

Learning and discovery. This theme emerged from primary codes including information seeking behavior, a desire for more knowledge, and experimenting with food. Learning about food was an extremely dominant aspect of being a 'Foodie' for all the study participants, with some arguing that one cannot be considered a 'Foodie' if he/she does not have a desire to enrich and regularly add to their knowledge of food. This pattern was represented throughout the data in relation to food preparation, cooking and consumption. A 28-year old male discussed that 'It's a good way of expressing some kind of creativity .. specially when cooking in a group, you kind of bounce ideas off each other and come up with new recipes..', which also touches on the third theme of inspirational influences. Another participant, a 32-year old female, stated that 'one of the biggest things about being a Foodie is trying out new and exciting foods'. This notion of discovery and exploration was not explicitly and actively mentioned in the various food definitions in extant literature, yet it was an integral part of this study. It was articulated by Johnston and Baumann (2014) in their study of Foodies. Another key element was the enthusiasm surrounding experimenting with different types of cuisines and cultural-specific palates, without following a set recipe.

Pleasure and enjoyment. The second emerging theme, in line with the earlier context of the study, was the enjoyment associated with the food consumption, but this study uncovered a pleasure beyond consumption. Two main sub-themes were identified: the pleasure of pleasing others, and active enjoyment.

The pleasure of pleasing others: this sub-theme was frequented among female participants in the study as they described pleasing others through their culinary skills as their greatest pleasure. One of them stated that 'cooking for others was one of the most enjoyable aspects of being me as a Foodie'. She added that 'it is the idea of going to prepare, cooking it .. taking my time, relaxing and then putting it on the table and then watching everyone enjoy it!'. It was also clear that there was immense inner satisfaction in observing significant others experience satiation and a disappointment when this was not the case. It links to the last theme of feeling a sense of belonging and connection with others through food. Though the cooking process was overlooked by studies in literature related to Foodies, it was a frequent pattern for many male participants and for most female participants in this study; in the case of male respondents, it was more about special occasions with a girlfriend or a special person, and in the case of females, it was about cooking for groups of family and friends. 
Active enjoyment: this sub-theme emerged in relation to codes such as 'food having a purpose', ' going beyond enjoying food as a fuel', 'living to eat rather than eating to live', suggesting that the pleasure and enjoyment encompassed an active involvement via 'food as a hobby' and through 'investing time in food', with a special interest in the notion of Food. The evolving ideas under this sub-theme were more intrinsically-driven and individual in relation to gratifying oneself, and taking pride in it as a pleasing accomplishment.

Inspirational influences. This third theme came out of a significant number of participants' quotes in summing up how a Foodie is sculpted. Every participant mentioned at least one of the following influences: popular culture, influence of others, and influence of health concerns. Several participants associated celebrity chefs and food programs with encouraging people to cook, and increasing the popularity of food and cooking. They described how they mostly engaged with media interest in food to enjoy the entertainment factor of the competitive shows and/or engage in the learning aspect of it. Those who were fond followers of food blogs on social media said they used the content for inspiration, to follow upcoming trends, and to get review opinions on tried-and-tested food suppliers and restaurants in their local areas. The use of blogging as an inspiration supports Cox and Blake's (2010) proposition that food blogging inspires Foodies; participants agreed that it spreads enthusiasm and thus drives the development of a popular gastronomic culture.

The influence of others, such as family and friends, marked the initial point for many of the participants' enduring interest in food. One of them said 'I just thought I liked food ....but that's probably what where I was raised taught me - not to be picky'. Another mentioned the opposite experience where his parents did not eat fish, which meant he did not eat it either as a child, then '...naturally, as I grew up I kind of broke away from that and then decided to try new things'. The influence of health featured also in relation to several dimensions, such as food intolerances leading to more attention to food ingredients, hence resulting in more interest in food as a whole. Nutrition came up in the coding as one of the motivations in finding out more about food, as the conception that 'you are what you eat' was repeatedly expressed, so more attention to healthy foods comprised an inspirational influence.

Quality. This theme was associated with primary codes of 'respect and caring for food' and 'appreciating food quality'. Sub-themes of freshness of food and the importance of quality in the purchase decision process emerged within. Provenance and source came up a lot in the interviews and focus group discussions in relation to trust in supermarket supplies, and preferring local markets and independent food providers. Themes of ethical trends related to choosing sustainable food and engaging with sustainable consumption were weakly identified and only acknowledged as a side possibility for some participants; no particularly strong views were expressed for preferring Organic or Fairtrade foods, yet supporting local farmers through buying local foods was favored whenever possible. 
Experiencing food as an individual and in connection with others. In the last theme, eating in and eating out arose as key sub-themes. Some participants reflected on their Foodie experience being related to eating in as an in-house involvement, expressing it as related to the desire for comfort and relaxation. The idea of cooking food was expressed as 'something that calms me down', 'it's a bit of a therapy for me as it's my time to relax', expressing individual emotions linked with an inner sense of connecting with the self through being a Foodie. A 30-year old female participant said 'I like cooking with myself', whereas another 23-year old male said 'For me it's a completely individual thing. If I could be on my own in the kitchen when I'm cooking, then that will be lovely!' Eating out at high-end restaurants in the company of others to try out new foods or enjoy an occasion was paired with factors such as learning, appreciation and enrichment; it was stated by many that eating out does not automatically make someone a Foodie as it may be a status thing 'just because they can', and not a way for furthering a Foodie identity.

The latter perception of self-identity was emphasized in various respects in the data, as participants associated being a Foodie with their self-distinctiveness in differing ways. Some of it came with the passion and emotion it initiated, while for others it developed in being part of the Foodie culture; one of the participants puts it as '...many people have particular talents like singing and dancing, others don't...like me. I don't, so it's a way ... one of the ways to express myself'. The identity accompanying self-perception of being a Foodie as well as labelling and defining oneself as one was confidently depicted and established by all participants, which is consistent with Euromonitor's report (2013a) postulating that the term is a label that becomes a part of one's identity.

\section{DISCUSSION AND CONCLUSIONS}

Results reflect that the term Foodie cannot be used as an implicit definition of someone 'simply interested in food'; the capacity of the Foodie was found to be dependent on how involved the individual with along the five established themes and the importance one places on them. It implies that there might be different levels of Foodies, thus leading to a start on developing a Foodie Typology. At some level, consumers consider it an inner connection with the self, demarcating a self-identity that they can identify with in tagging themselves 'Foodies'. Their self-pleasing Foodie practices bring them joy at the individual level, where engaging with its notions is therapeutic and a calming inner endeavor. In their variation, some Foodies may be active learners of new food trends and cuisines but have a passive presence online - being more on the receiving than the sending end. At another level, it might become a hobby, where more time and effort is invested in the discovery and experimentation, whether in eating in or out.

On the other hand, other types of Foodies find this movement a means of connecting with others, belonging to a cult of individuals who can share evolving food experiences and enjoying cooking for others as they derive satisfaction out of the pleasure their food gives away. This group may be more active participants in the Foodie popular culture, with an active presence online. The Foodies' Typology may also be linked with different spending powers as part of profiling subconsumer groups; this was reflected in the Quality theme, where some of its implications linked with affordability. The nutritional dimension came up in the discussion as an inherent part of looking deep and with passion into what one eats, but body image could be a deterrent, for some people, in accepting the 'Foodie label' according to some participants' comments; this is based on the fallacy associating Foodies with consuming too much food. This perspective was 
criticized as incorrect given that Foodies were designated as food-responsible consumers. The data also indicates that food industry professionals can be considered higher-level Foodies, as elucidated by one of participants in: 'I look at a food critic and they're definitely a foodie to me, but I don't know, it's quite hard... I think there might be different levels of foodies'.

\section{IMPLICATIONS AND LIMITATIONS}

The study poses many implications for marketers and food researchers. It provides insights into Foodie attitudes, perceptions and aspirations; however, it also opens questions to be addressed through further research. Foodies do not see food as a commodity, but as an ordeal far greater than just taste or simple value. Through the five emergent themes in this exploratory study, marketers are offered a clearer appreciation of Foodies in the UK, which might help in building richer profiles of levels of Foodies, representing different consumer sub-segments. These can evolve around levels of providing food products that allow the individual an emotional investment in consumption experiences at various tiers. Hence, different marketing and communication programs can be tailored to suit their needs, sense of self and connectivity with others.

For example, Foodies who look for inspiration via connecting with others and sharing an evolving 'Foodie's popular culture' may require different marketing programs to those who enjoy cooking as an individualistic experience that expresses their inner sense of self. For the former, using social media to promote Foodie ideas and products is more suitable as they connect with one another and with food brands online via blogs and forums; for the latter, a magazine advert that promotes Foodie products and 'Foodie cooking tips' that can be read in personal relaxed time is likely to be more effective in reaching this target sub-segment. On the other hand, Foodies who enjoy experimenting with food and discovering new cuisines are likely to be inspired by food industry professionals viewed as 'higher-level Foodies'; this sub-segment watches TV cooking programs and competitive cookery shows such as MasterChef and Saturday Kitchen, which are proving to be increasingly popular in their viewership (Vincent, Lawrence, Runcie and Ward 2013). Product placement during these TV shows has a high likelihood of getting the attention of this Foodie consumer, and the promotional message is likely to engage his/her interest. As for Foodies who seek quality in food consumption, go through articulate food purchase decision processes and look for provenance of food supplies, it is imperative for marketers to make such information readily available to them; this Foodie consumer subsegment engages in extensive problem-solving in food purchase decision-making, and they experience both high purchase decision involvement and high product category involvement (Schiffman, Kanuk and Hansen 2012).

The current study as an initial exploratory investigation is limited to a small sample, which can be further expanded in future research to dig deeper into the subjectivities of the 'Foodies' on a wider scale. For instance, the Foodie notion in being a personal attribution to the individual may pose a challenge in explaining the collective dimension involved - an area that calls for further study. Investigating the eminence of the self-identity versus the sense of connection and belonging in the Foodie world along varied levels of the key emergent themes can assist in shaping a better and deeper understanding of the complexities of the Foodie notion, its typologies and expanding global movement. 


\section{REFERENCES}

Appadurai, A. (1996). Modernity at large: Cultural dimensions of globalization. University of Minnesota Press.

Barbour, R. S. (2001). Checklists for improving rigour in qualitative research: a case of the tail wagging the dog? British Medical Journal, 322(7294), 1115-1117.

Bourdieu, P. (1984). Distinction: A social critique of the judgement of taste. Harvard University Press.

Braun, V., \& Clarke, V. (2006). Using thematic analysis in psychology. Qualitative Research in Psychology, 3(2), 77-101.

Cairns, K., Johnston, J., \& Baumann, S. (2010). Caring about food doing gender in the Foodie kitchen. Gender \& Society, 24(5), 591-615.

Cox, A. M., \& Blake, M. K. (2011). Information and food blogging as serious leisure. In P. Willett (Eds.), Aslib proceedings, Vol. 63, Emerald Group Publishing Limited, March (2/3), 204220.

DEFRA (2014). Food Statistics Pocketbook 2013 - in year update. Department for Environment, Food and Rural Affairs. Retrieved July 15, 2015 from https://www.gov.uk/government/uploads/system/uploads/attachment_data/file/315418/foodpock etbook-2013update-29may14

Euromonitor (2013a). Food trends and consumers in Europe: Pick your food fad. Retrieved August 20, 2015 from http://www.portal.euromonitor.com.atlas.worc.ac.uk/Portal/Pages/Search/SearchResultsList.aspx

Euromonitor (2013b), Consumer lifestyles in the United Kingdom. Retrieved August 30, 2015 from http://www.portal.euromonitor.com.atlas.worc.ac.uk/Portal/Pages/Search/SearchResultsList.aspx 
Fischler, C. (1988). Food, self and identity. Social Science Information, 27(2), 275-292.

Hennink, M., Hutter, I., \& Bailey, A. (2011). Qualitative Research Methods. Sage.

Johnston, J., \& Baumann, S. (2014). Foodies: Democracy and Distinction in the Gourmet Foodscape. Routledge.

Saunders, M., Lewis, P., \& Thornhill, A. (2012). Research methods for business students, $6^{\text {th }}$ ed., Pearson Education: UK.

Oxford Dictionary (2014, Online). Foodie. Retrieved September 15, 2015 from http://www.oxforddictionaries.com/definition/english/foodie?q=foodie.

Poole, S. (2012). Let's start the Foodie backlash. The Guardian, Retrieved September 15, 2015 from http://www.theguardian.com/books/2012/sep/28/lets-start-foodie-backlash

Probyn, E. (1999). Beyond food/sex eating and an ethics of existence. Theory, Culture \& Society, 16(2), 215-228.

Schiffman, L., Kanuk, L., \& Hansen, H. (2012). Consumer Behaviour: A European Outlook, International Edition. Upper Saddle River: Pearson

Sloan, A. E. (2013). The Foodie Phenomenon. Food Technology, 67(2), 18.

Vincent, A., Lawrence, B., Runcie, C., \& Ward, R. (2013). The 10 most influential British cookery shows. The Telegraph. Retrieved March 23, 2016 from http://www.telegraph.co.uk/culture/tvandradio/10394111/The-10-most-influential-Britishcookery-shows.html

Yue, A. (2003). Eating. In F. Martin (Eds.), Interpreting Everyday Culture (pp.159-172). Oxford University Press. 


\begin{tabular}{|c|c|c|}
\hline Themes & Sub-themes & Related Findings \\
\hline $\begin{array}{c}\text { Learning and } \\
\text { Discovery }\end{array}$ & $\begin{array}{l}* \text { Information } \\
\text { seeking behavior } \\
* \text { Experimenting } \\
\text { with food }\end{array}$ & $\begin{array}{l}\text { A desire for more knowledge and experimenting with } \\
\text { food towards enriched information about food was an } \\
\text { extremely dominant aspect of being a Foodie for all } \\
\text { participants. It touches on the third theme of } \\
\text { inspirational influences as it included exploring 'with } \\
\text { others'. Enthusiasm surrounding experimenting with } \\
\text { different types of cuisines and cultural foods, without } \\
\text { following a set recipe, was also a key pattern. }\end{array}$ \\
\hline $\begin{array}{c}\text { Pleasure and } \\
\text { Enjoyment }\end{array}$ & $\begin{array}{l}* \text { Pleasure of } \\
\text { pleasing others } \\
* \text { Active enjoyment }\end{array}$ & $\begin{array}{l}\text { The pleasure of pleasing others was a theme } \\
\text { frequented by female participants in the study. It was } \\
\text { depicted in immense satisfaction in observing other } \\
\text { enjoy the cooked food, and a disappointment when } \\
\text { this was not the case. For males it was more about } \\
\text { special occasions with a girlfriend or a special } \\
\text { person. It highlights relishing a sense of belonging } \\
\text { and connection with others. Active enjoyment was } \\
\text { embedded in food having a purpose, food as a hobby, } \\
\text { investing time in food' and intrinsically felt as self- } \\
\text { gratification and personal pride. }\end{array}$ \\
\hline $\begin{array}{l}\text { Inspirational } \\
\text { Influences }\end{array}$ & $\begin{array}{l}\text { * Popular culture } \\
\text { * Influence of others } \\
\text { * Influence of health }\end{array}$ & $\begin{array}{l}\text { Every participant mentioned at least one of the sub- } \\
\text { themes. Engaging with the popular culture online } \\
\text { through blogging or consuming media was } \\
\text { highlighted. The influence of others, such as family } \\
\text { and friends, marked the starting point for many of the } \\
\text { participants' enduring interest in food. The influence } \\
\text { of health featured in relation to food intolerances } \\
\text { leading to interest in food as a whole. Nutrition was } \\
\text { highlighted in recurrence of 'you are what you eat'. }\end{array}$ \\
\hline Quality & $\begin{array}{l}\text { * Freshness of food } \\
\text { * Importance of } \\
\text { quality in the } \\
\text { purchase decision }\end{array}$ & $\begin{array}{l}\text { Results highlighted respect and caring for food, } \\
\text { appreciating food quality, searching for provenance } \\
\text { and source of food supplies, and preferring local } \\
\text { markets and independent suppliers. } \\
\text { Ethical trends featured weakly in the responses, and } \\
\text { were only recognized as a side possibility for some } \\
\text { participants through buying local food when possible. }\end{array}$ \\
\hline $\begin{array}{l}\text { Experiencing } \\
\text { Food as an } \\
\text { Individual \& } \\
\text { in Connection } \\
\text { with Others }\end{array}$ & $\begin{array}{l}* \text { Cooking and the } \\
\text { individual internal } \\
\text { experience involved } \\
\text { (eating in) } \\
\text { * Eating out }\end{array}$ & $\begin{array}{l}\text { Foodie experience was connected to eating-in as an } \\
\text { in-house involvement, expressing it as related to the } \\
\text { desire for comfort and relaxation. Eating-out at high- } \\
\text { end restaurants with others to try out new } \\
\text { foods/enjoy an occasion was paired with learning and } \\
\text { enrichment. The sense of identity accompanying self- } \\
\text { perception as a Foodie was a dominant view. }\end{array}$ \\
\hline
\end{tabular}

Table 1: Summary of Research Results 